\title{
Subclinical hypothyroidism in childhood, treatment or only follow-up?
}

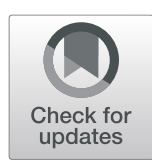

\author{
Marta Murillo-Vallés ${ }^{1}$, Santiago Martinez ${ }^{1}$, Cristina Aguilar-Riera ${ }^{2 *}$ (D), Miguel Angel Garcia-Martin ${ }^{3}$, \\ Joan Bel-Comós ${ }^{1}$ and Maria Luisa Granada Ybern ${ }^{3}$
}

\begin{abstract}
Background: Subclinical hypothyroidism (SH) is defined as serum levels of thyroid-stimulating hormone (TSH) above the upper limit with normal concentrations of free T4 (fT4). Its management remains challenging. The aim of the study was to evaluate clinical and laboratory findings as well as the clinical course of children with SH followed in a third level hospital. Sixty-five patients aged between 2 and 18 years old were retrospectively studied.

Methods: The patients were followed for a median period of 9 months (range 6 months to 24 months). Those who normalized TSH levels were discharged (Group 1). If TSH persisted mildly elevated $(5-10 \mu \mathrm{UI} / \mathrm{mL}$ ) with normal fT4 and negative TPOAb/TgAb, they were classified as Group 2 and followed semi-annually without treatment. Those patients whose $\mathrm{TSH}$ raised $\geq 10 \mu \mathrm{UI} / \mathrm{mL}$ or who maintained TSH $5-10 \mu \mathrm{UI} / \mathrm{mL}$ and positive $\mathrm{TPOAb} / \mathrm{TgAb}$ were considered suitable for thyroxin therapy (Group 3, G3).
\end{abstract}

Results: In 89\% of our patients, TSH concentrations spontaneously reverted to normality or remained stable without treatment (Groups 1 and 2), whereas less than 11\% progressed to clinical hypothyroidism (Group 3). Baseline TSH was significantly lower in group 1 than in group 3. In group 3 the prevalence of female sex (71\%) was higher and TPO antibodies were present in $85 \%$ of patients. The risk of developing overt hypothyroidism in patients with positive anti-thyroid antibodies respect to those who normalized TSH was 45 (95\%Cl 6.5-312.5).

Conclusion: Baseline TSH, female sex and the presence of thyroid autoimmunity were the best predictors of the evolution to SH over time.

Keywords: Subclinical hypothyroidism, Cut-off, Child, Screening

\section{Background}

Subclinical hypothyroidism (SH), also known as isolated hyperthyrotropinemia, is defined as serum thyroidstimulating hormone (TSH) concentrations above the upper limit of the reference range and normal concentrations of free T4 (fT4). This situation occurs in less than $3 \%$ of children and adolescents $[1,2]$, but it is a cause of concern for parents and primary care physicians

\footnotetext{
* Correspondence: c aguilarriera@hotmail.com

${ }^{2}$ Pediatrics Section, Germans Trias i Pujol University Hospital, Autonomous University of Barcelona, Badalona, Spain

Full list of author information is available at the end of the article
}

and represents a frequent cause of referral to a pediatric endocrinologist.

TSH normal range $(0.4-0.5 \mu \mathrm{UI} / \mathrm{mL}$ to $4.0-5.0 \mu \mathrm{UI} /$ $\mathrm{mL}$ ) depends on the method used, with large variations found between different TSH assays. Idiopathic $\mathrm{SH}$ is characterized by mild elevations of TSH concentrations levels $(5-10 \mu \mathrm{UI} / \mathrm{mL})$ with peripheral hormones fT4 and triiodothyronine within normal ranges, absence of thyroid autoimmunity or other conditions that may account for the increase in TSH, such as certain medications or genetic disorders (Down syndrome, Pseudohypoparathyroidism and others), and without clinical signs or symptoms of thyroid failure. 
The natural course of idiopathic $\mathrm{SH}$ is unclear. Most patients normalize TSH values and a small percentage progresses to overt hypothyroidism [3-7]. The risk of progression to overt hypothyroidism depends on the cause of $\mathrm{SH}$ with high risk in autoimmune forms. There is a lack of conclusive studies that determine whether these children with $\mathrm{SH}$ might benefit from levothyroxine treatment [7-9].

On the other hand, adverse health outcomes of $\mathrm{SH}$ in childhood remain controversial. Although it might not produce adverse effects on growing and development processes $[5,8,10]$, it has been recently associated with overweight/obesity and metabolic abnormalities [11, 12]. Nevertheless, prospective studies that determine those deleterious effects are lacking.

This study aimed to analyze the characteristics and natural evolution of a cohort of children with $\mathrm{SH}$ referred to a third level hospital.

\section{Methods}

We analyzed retrospectively patients who were diagnosed with $\mathrm{SH}$ and referred to the Endocrinology Unit of our hospital between 2014 and 2018. SH was defined as TSH concentration mildly elevated $(5-10 \mu \mathrm{UI} / \mathrm{mL})$ with fT4 within the normal reference range $(0.7-1.48 \mathrm{ng} / \mathrm{dL})$. Patients were assessed at the time of diagnosis, at month 3 and every 6 months during follow-up if necessary.

\section{Patients}

Inclusion criteria were as follows: patients referred for $\mathrm{SH}$ aged 2 to 18 years old with at least two analytical records: one at the time of diagnosis and another one during the follow-up. Patients under 2-years-old and who received pharmacological treatment that could alter the TSH concentrations (anticonvulsants, antipsychotics, glucocorticoids, iodine or iodine-rich diet) were excluded. We also excluded patients with genetic syndromes or under an acute disease. All patients resided in an area by the Mediterranean Sea in an iodine-sufficient population.

All patients had a complete clinical record, physical examination including anthropometric characteristics (height, weight), and thyroid exploration at the time of diagnosis and during follow-up visits. We calculated body mass index (BMI) and represented the results as standard deviation (SD) according to age and sex. Obesity was considered if the BMI-SD was above 2 for the reference population. Short stature was considered if the height-SD was below 2 for the reference population.

Thyroid function test consisted of TSH, fT4 and thyroid autoantibodies (anti-peroxidase (TPOAb) and antithyroglobulin (TgAb)). If necessary -p.e. with palpable goiter, persisted elevated TSH or positive autoimmunity-, a thyroid ultrasound was made to assess thyroid size and echogenicity.
All patients had an initial TSH concentration mildly elevated $(5-10 \mu \mathrm{UI} / \mathrm{mL})$ with $\mathrm{fT} 4$ within the normal reference range. The patients were followed for a median period of 9 months (range 6-24 months). Those patients who normalized TSH levels at the follow-up were discharged (Group 1, G1); follow-up median period 6 months (range 3-9 months) whereas those who persisted with elevated TSH were followed. If TSH persisted mildly elevated (5$10 \mu \mathrm{UI} / \mathrm{mL}$ ) with normal fT4 and negative TPOAb/TgAb, they were classified as Group 2 (G2) and followed semiannually without treatment, follow-up median period 12 months (range 9-24 months). Those patients whose TSH raised $\geq 10 \mu \mathrm{UI} / \mathrm{mL}$ or who maintained TSH $5-10 \mu \mathrm{UI} / \mathrm{mL}$ and positive TPOAb/TgAb (regardless fT4 levels) were considered overt hypothyroidism and suitable for thyroxin replacement therapy due to hypothyroidism/thyroiditis (Group 3, G3), follow-up median period 12 months (range 9-24 months).

\section{Biochemical and hormonal determinations}

Blood samples were drawn at 8 a.m. after an overnight fast. Samples were centrifuged and sera kept frozen at $20^{\circ} \mathrm{C}$ until analysis. Analysis of serum TSH was performed with CLIA with the aid of an Abbott ARCHITECT instrument (Abbott Diagnostics Division). Total coefficient of variation $(\mathrm{CV})$ was $<3.3 \%$, functional sensitivity was $0.0038 \mu \mathrm{UI} / \mathrm{mL}$; reference range $[99 \%$ confidence interval $(\mathrm{CI})]$ : $0.35-4.94 \mu \mathrm{UI} / \mathrm{mL}$; fT4 was measured by Abbott ARCHITECT instrument (Abbott Diagnostics Division; total CV was $<7 \%$, sensitivity of the assay was $<$ $0.4 \mathrm{ng} / \mathrm{dL}$; reference range $(99 \% \mathrm{CI}): 0.70-1.48 \mathrm{ng} / \mathrm{dL}$ (conversion factor $\mathrm{ng} / \mathrm{dL}{ }^{*} 12.87=\mathrm{pmol} / \mathrm{L}$ ). TPOAb were measured by an Abbott ARCHITECT instrument (Abbott Diagnostics Division). Total CV was $<7.6 \%$, sensitivity of the assay was $0.16 \mathrm{IU} / \mathrm{mL}$; reference range: $<5.61 \mathrm{IU} / \mathrm{mL}$.

\section{Statistical analyses}

The normality of the evaluated variables was established using the Kolmogorov-Smirnov test. Quantitative variables are presented as mean $\pm \mathrm{SD}$ or as median (interquartile range: 25th-75th percentile) whereas qualitative variables are expressed as percentages. Differences among groups were assessed by the ANOVA or the non-parametric Kruskal Wallis test. To determine differences between groups, the Student's T test or nonparametric Mann-Whitney $U$ test was used, and to compare variables at baseline and at follow-up, we used the Wilcoxon test. Differences in proportions were analyzed by the $\chi^{2}$ test or Ficher's exact test. All tests were two-tailed and a $\mathrm{p}$ value $<0.05$ was considered statistically significant. Statistical analyses were performed using the SPSS package 12.0 and MedCalc Software 12.7.0 (Acacialaan 22, B-8400 Ostend, Belgium). 
The relative risk was calculated as the ratio of the proportions of cases having a positive antibodies in the G3 group (6 out of 7), respect to group G1 (0 out of 44). This test was performed with the aid of MedCalc Statistical Software version 19.1.7 (MedCalc Software Ltd., Ostend, Belgium; https://www.medcalc.org; 2020) The program calculates the relative risk with $95 \%$ confidence interval, the z-statistic and associated P-value. If P is less than 0.05, it can be concluded that the proportions are significantly different in the two groups, and there is an increased risk in one group compared to the other.

The study was approved by the Ethics Committee. All patients or legal surrogates gave informed consent prior to participation.

\section{Results}

The study included 65 patients diagnosed with SH (51\% female). The median age at diagnosis was 7.75 (4.4-9.17) years old. Clinical and laboratory findings at the time of diagnosis are shown in Table 1 . The main reason for the study of thyroid function was routine analytical $(41,5 \%$, n: 27$)$, obesity $(13,8 \%, n: 9)$, short stature $(12.3 \%, n: 8)$, asthenia $(10.7 \%, \mathrm{n}: 7)$ or others $(18.4 \%, \mathrm{n}: 14)$.

Table 1 Anthropometrical, clinical and laboratory characteristics at baseline

\begin{tabular}{ll}
\hline n: 65 & $33(51 \%)$ \\
\hline Female (\%) & $7.75(4.4-9.17)$ \\
Age (years) & \\
Referral for analytic study: & $27(41.5 \%)$ \\
Routine & $9(13.8 \%)$ \\
Obesity & $8(12.3 \%)$ \\
Short stature & $7(10.7 \%)$ \\
Asthenia & $14(21,5 \%)$ \\
Others & \\
Clinical features: & $-0.5[(-1.09)-(+0.86)]$ \\
BMI-SD & $-0.39[-0.99)-(+1.2)]$ \\
Weight-SD & $-0.47[(-1.38)-(+0.75)]$ \\
Height-SD & $9(13.8 \%)$ \\
Obesity (BMI-SD $\geq 2)$ & $8(12.3 \%)$ \\
Short stature (<2SD) & 0 \\
Goiter & $8(12.3 \%)$ \\
Familiar history (Autoimmune disease) & \\
Laboratory results: & $6.7(6.1-7.8)$ \\
TSH ( $\mu U$ Ul/mL) & $1.1(1.0-1.3)$ \\
Free thyroxin (ng/dL) & $6(9.2 \%)$ \\
TPO positivity & $23(35,3 \%)$ \\
US performed (\%) & \\
\hline Data are expressed as medan & \\
\hline &
\end{tabular}

Data are expressed as median (IQR) or percentage (\%)
Regarding clinical characteristics, the medians of weight, height and BMI were within the normal ranges $(-0.39 \mathrm{SD}$, $-0.47 \mathrm{SD}$ and $-0.5 \mathrm{SD}$ respectively) with $13.8 \%$ of obesity and $12,3 \%$ of patients with short stature. No patient had goiter on physical examination.

There was a family history of thyroid disease in 8 cases (12.3\%).

At the time of diagnosis, all patients were asymptomatic of thyroid dysfunction, and these patients were observed without treatment.

Table 2 shows the clinical and laboratory characteristics of patients classified into 3 different groups according to evolution. TSH concentrations returned to normal ranges in 44 patients (67.6\%) (G1), 14 patients (21.5\%) maintained slightly elevated TSH concentrations with negative thyroid antibodies (G2) and 7 patients (10.7\%) had $\mathrm{TSH} \geq 10 \mu \mathrm{UI} / \mathrm{mL}$ or $\mathrm{TSH} 5-10 \mu \mathrm{UI} / \mathrm{mL}$ and positive TPOAb/TgAb (6 patients) (G3).

The prevalence of females was higher in the G3 (71\%), but in the other two groups, the distribution was similar (50\% in G1 and 57\% G2). Regarding the age as well as a family history of autoimmune diseases, no differences were found among the 3 groups.

Mean baseline TSH concentrations differed among the 3 groups $(\mathrm{p}=0.012)$, significant differences were found in TSH values between G1 and G3 ( F = 4.768; p = 0.016) whereas no differences were found between G1 and G2 or between G2 and G3. No differences were found in fT4 concentrations at baseline among the 3 groups $(\mathrm{F}=$ 3.083; $\mathrm{p}=0.053$ ) (Fig. 1). The percentage change of TSH at follow-up with respect to baseline was $47.8 \%$ decrease in group 1, a $6.9 \%$ decrease in group 2 and a $24.7 \%$ increase in group 3 (Table 2).

BMI evolution was evaluated during the study and no significant difference was found in obesity (BMI-SD > 2) prevalence during follow-up in all patients (13,8 to $10.7 \%)$. In terms of height there were no differences.

Thyroid autoimmunity was observed in $85 \%$ of patients of G3 and none of G1 and G2 (p > 0.001). The risk of developing overt hypothyroidism in patients with positive anti-thyroid antibodies with respect to those who normalized TSH was 45 (95\%CI 6.5-312.5).

Of all the patients, 35,3\% underwent a thyroid ultrasound and a structure suggestive of thyroiditis (heterogeneous, hypoechoic and in some cases enlarged ultrasound pattern) was found in 6 patients, all in the G3. There was 1 patient with nodules on ultrasound without other significant findings; the rest of the patients presented a normal ultrasound.

\section{Discussion}

In general terms, $\mathrm{SH}$ seems to affect less than $3 \%$ of the child population and usually displays a natural course towards the maintenance or spontaneous resolution in 
Table 2 Clinical and laboratory characteristics among groups

\begin{tabular}{|c|c|c|c|c|}
\hline & Group 1 & Group 2 & Group 3 & Significance \\
\hline $\mathrm{N}$ & $44(67,6 \%)$ & $14(21,5 \%)$ & $7(10,7 \%)$ & \\
\hline Female & $51.2 \%$ & $42.9 \%$ & $71.4 \%$ & N.S. \\
\hline Age at baseline (years) & $6.7(4.0-9.2)$ & $8.17(6.48-9.48)$ & $8.17(7.4-9.17)$ & N.S. \\
\hline Familiar History (Autoimmune disease) & $11.4 \%$ & $7.1 \%$ & $14.3 \%$ & N.S. \\
\hline $\mathrm{TSH}(\mu \mathrm{UI} / \mathrm{mL})$ at baseline & $6.6(6.02-7.35)^{\mathrm{a}}$ & $7.05(6.07-8.12)$ & $8.2(6.7-9.4)$ & 0.012 \\
\hline Free thyroxin $(\mathrm{ng} / \mathrm{dL})$ at baseline & $1.15(1.02-1.3)$ & $1.0(0.95-1.3)$ & 1.0(0.88-1.1) & 0.03 \\
\hline TSH $(\mu \mathrm{UI} / \mathrm{mL})$ at follow-up & $3.7(2.94-4.2)^{b, c}$ & $6.1(5.17-8.0)^{d}$ & $1.0(088-1.1)$ & $<0.001$ \\
\hline Free thyroxin $(\mathrm{ng} / \mathrm{dL})$ at follow-up & $1.07(0.98-1.2)$ & 1.04(0.9-1.19) & $0.88(0.83-1.1)$ & N.S. \\
\hline Percentage change in TSH (baseline vs follow up) & $\begin{array}{l}-47.8 \\
((-35.3)-(-56.7))^{\mathrm{b}, \mathrm{c}}\end{array}$ & $-6.9((-17.3)-1.9)^{d}$ & $24.7(14.6-95.5)$ & $<0.001$ \\
\hline BMI-SD & $-0.61[(-1.1)-0.83]$ & $0.21[(-0.62)-1.18]$ & $0.43[(-0.68)-0.85]$ & NS \\
\hline Obesity (BMI $\geq 2$ SD) & $6(13,6 \%)$ & $3(21,4 \%)$ & $0(0 \%)$ & N.S. \\
\hline Height-SD & $-0.85[(-0.98)-0.67]$ & $-0.45[(2.27)-0.82]$ & $0.35[(-2.2)-1.4]$ & N.S. \\
\hline Height-SD $<2$ SD & $1(2,2 \%)$ & $5(35,7 \%)$ & $2(28,5 \%)$ & N.S. \\
\hline TPOAb/TgAb positivity & $0(0 \%)$ & $0(0 \%)$ & $6(85 \%)$ & 0.001 \\
\hline Performed US & $10(22 \%)$ & $6(42 \%)$ & $7(100 \%)$ & \\
\hline Tiroiditis by US & $0(0 \%)$ & $1(16 \%)$ & $6(83 \%)$ & 0.04 \\
\hline
\end{tabular}

N.S.: non significant

${ }^{a}: p<0.016$ group 1 vs group 3

${ }^{b}: p<0.001$ group 1 vs group 2

${ }^{c} p<0.001$ group 1 vs group 3

${ }^{d}: p<0.001$ group 2 vs group 3

Quantitative variables are expressed as median (IQ range p25-p75)

Qualitative variables are expressed as N (\%)

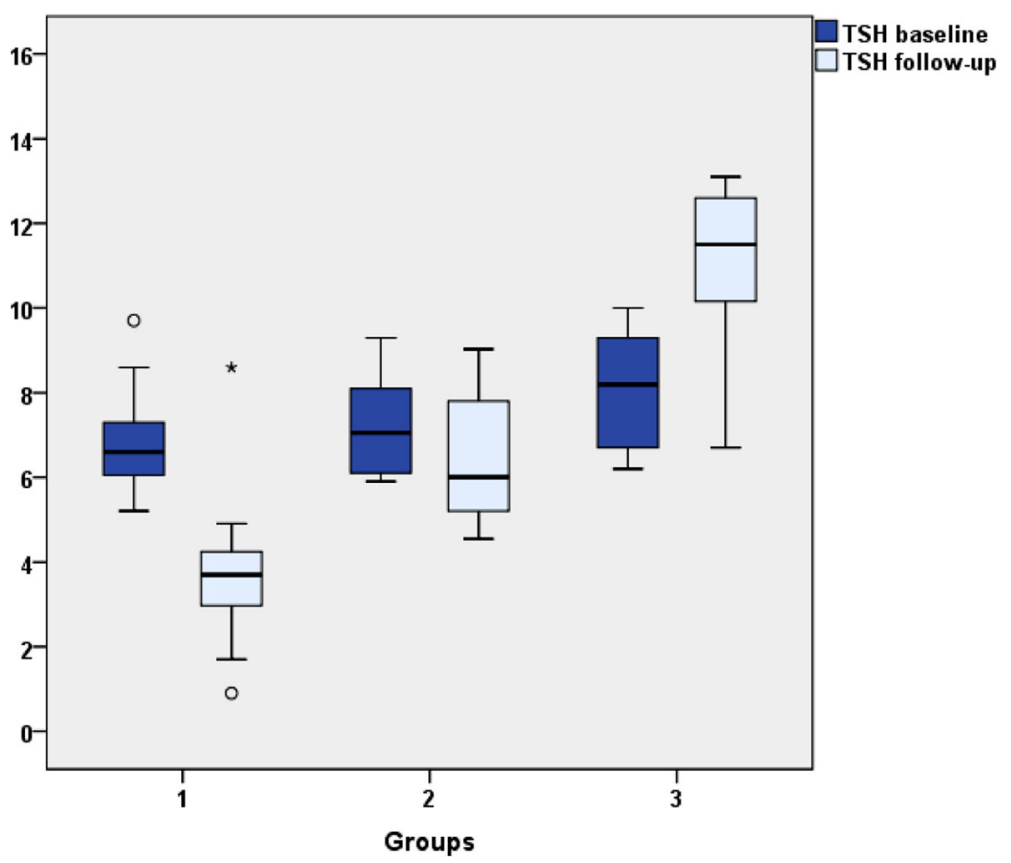

Fig. 1 TSH values at baseline and follow-up. Patients were classified into three groups according TSH levels at the end of the follow up. Group 1

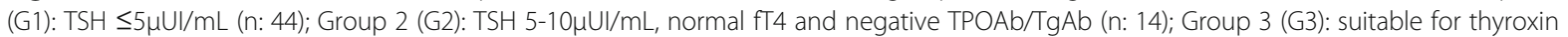
therapy due to $\mathrm{TSH} \geq 10 \mu \mathrm{UI} / \mathrm{mL}$ or TSH $5-10 \mu \mathrm{UI} / \mathrm{mL}$ and positive TPOAb/TgAb (n: 7) 
variable time in most cases (68-88\%) and only a few cases progress to overt hypothyroidism or autoimmune thyroiditis. There are few studies to date that evaluate $\mathrm{SH}$ and its evolution in childhood $[5,10,13,14]$. In our study, most of the patients either normalized their TSH levels or maintained their TSH levels under subclinical range values $(89 \%)$. Only a small percentage presented overt hypothyroidism or autoimmune thyroiditis and needed treatment (11\%). These data are similar to those of a 2-year prospective study presented by Wasniewska et al., in which $88 \%$ of patients normalized o preserved their TSH levels and 12\% developed hypothyroidism [5].

In an attempt to anticipate events, Lazar et al. found that predictive factors for sustained abnormal TSH levels were initial TSH $>7.5 \mu \mathrm{UI} / \mathrm{mL}$ and female gender [1]. Recently, Gammons et al. concluded that a TSH $>8 \mu \mathrm{UI} /$ $\mathrm{mL}$ would be the cut-off point to refer to a pediatric endocrinologist for evaluation and management [15]. Although, because of the small number of patients, an AUC could not be assessed to determine the cutoff level of TSH that predicts evolution towards hypothyroidism, in our cohort baseline TSH levels of G3 were significantly higher.

Regarding the weight, in our study, no significant changes were detected between obesity prevalence at baseline and during follow-up in all the patients, and the BMI-SD did not worsen during follow-up in any patient. However, in the G2 group, those who persisted with a TSH $5-10 \mu \mathrm{UI} / \mathrm{mL}$ had a higher prevalence of obesity, which would suggest that it may have a role in increasing TSH levels. It is thought that the mildly elevated TSH is the consequence of obesity rather than the cause, as an attempt to increase energy expenditure, with an improvement of the thyroid function parameters when lowering the BMI, as has been mentioned on multiples studies [16-21]. Contrary to what one would expect, none of the patients with obesity belonged to the G3 with overt hypothyroidism.

It is known that autoimmunity is a key factor that determines the major progression to hypothyroidism. In our study, almost all patients in G3 met this condition and $71.4 \%$ were women, which is a distribution that already occurs in most autoimmune diseases. Our results are in agreement with Wasnieska et al. [22] who studied the long term evolution of a large cohort of girls with subclinical hypothyroidism and found that underlying Hashimoto thyroiditis was the main factor to become overtly hypothyroid or require L-T4 treatment. In fact, it has been reported that in children with Hashimoto thyroiditis the evolution of thyroid status is frequently characterized by a spontaneous worsening over time, even in the cases who initially present with a mild biochemical picture [23]. Lazarus et al. analyzed the results of $7 \mathrm{ob}-$ servational studies and showed that elevated TgAb and
$\mathrm{TPOAb}$ at diagnosis were associated with an increased risk of progression in some but not all studies [7].

Treatment with levothyroxine was initiated in all patients who presented TSH $\geq 10 \mu \mathrm{UI} / \mathrm{mL}$ or TSH $5-10 \mu \mathrm{UI} /$ $\mathrm{mL}$ and positive TPOAb/TgAb (G3). The dilemma arises in deciding whether patients with maintained mildly elevated TSH (G2) should be treated or not with levothyroxine and what benefits it can bring against possible consequences of $\mathrm{SH}$, since good-quality studies examining the effect of treatment of $\mathrm{SH}$ in children are lacking [9, 24-26]. In our case, no patients were treated since none presented associated symptoms or alterations that could be related to it.

The current study has its limitations. For instance, it is a retrospective study with a small number of patients, and genetic causes such as alterations in the TSH receptor that could explain mildly elevated TSH have not been investigated. On the other hand, the possible impact on growth and intellectual development has not been assessed in this study.

\section{Conclusion}

Although $\mathrm{SH}$ in childhood is a frequent issue and a matter of concern between primary care pediatrics, it seems to be a benign and remitting condition; based on our results and in comparison, with the literature, expectant behavior is the best option, always individualizing each patient. Perhaps repeating a second determination by the primary care pediatrician of TSH and fT4 in 1-3 months and if alteration persists refer to specialist many cases could be resolved and, therefore, save time and resources.

However, in the case of pediatric $\mathrm{SH}$, prospective studies are lacking to determine a sensitive and specific level of TSH to predict the progression to hypothyroidism. It is important to determine if it is a process with negative or positive autoimmunity, since on this latter case, the probability of progression to hypothyroidism is greater. As seen in the current study, baseline TSH, female sex and the presence of thyroid autoimmunity were the best predictors of the evolution to $\mathrm{SH}$ over time.

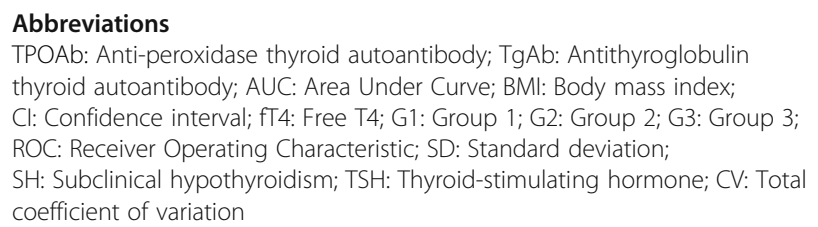

We thank Dr. Silvia Rodriguez-Fernandez (Immunology Section, Germans Trias i Pujol Research Institute, Badalona, Spain) for her help proofreading this work.

\section{Authors' contributions}

MM conceptualized and designed the study, proposed the new terminology, controlled the analyses, drafted the first and final manuscript. SM organized 
the data collection, carried out the initial analyses, and drafted the initial manuscript. CA organized the data collection, carried out the initial analyses and submitted the manuscript. MG performed the statistical analysis. JB reviewed the manuscript and approved the final manuscript. MG reviewed the statistical analysis and reviewed the final manuscript. All authors were involved in writing the manuscript and approved the final version.

\section{Funding}

There is no funding source.

\section{Availability of data and materials}

The datasets during and/or analyzed during the current study are available from the corresponding author on reasonable request.

\section{Ethics approval and consent to participate}

This article was approved by the ethics committee Centre de comitè d'ètica de la Investigació Clínica Hospital Universitari Germans Tries i Pujol (CEIHUGTiP) as it contains human data. Informed verbal consent was obtained from all individual participants or legal surrogates included in the study to use their data. The ethics committee agreed as it is a prospective study without intervention and with anonymous data.

\section{Consent for publication}

Not applicable.

\section{Competing interests}

The authors declare that they have no competing interests.

\section{Author details}

${ }^{1}$ Endocrinology Unit. Pediatrics Section, Germans Trias i Pujol University Hospital, Autonomous University of Barcelona, Badalona, Spain. ${ }^{2}$ Pediatrics Section, Germans Trias i Pujol University Hospital, Autonomous University of Barcelona, Badalona, Spain. ${ }^{3}$ Clinical Biochemistry Department, Germans Trias i Pujol University Hospital, Autonomous University of Barcelona, Badalona, Spain.

Received: 28 February 2020 Accepted: 27 May 2020 Published online: 06 June 2020

\section{References}

1. Lazar L, Frumkin RB-D, Battat E, Lebenthal Y, Phillip M, Meyerovitch J. Natural history of thyroid function tests over 5 years in a large pediatric cohort. J Clin Endocrinol Metab. 2009 May;94(5):1678-82.

2. Wu T, Flowers JW, Tudiver F, Wilson JL, Punyasavatsut N. Subclinical thyroid disorders and cognitive performance among adolescents in the United States. BMC Pediatr. 2006 Apr 19;6(1):12.

3. Moore DC. Natural course of "subclinical" hypothyroidism in childhood and adolescence. Arch Pediatr Adolesc Med. 1996 Mar;150(3):293-7.

4. Monzani A, Prodam F, Rapa A, Moia S, Agarla V, Bellone S, et al. Endocrine disorders in childhood and adolescence. Natural history of subclinical hypothyroidism in children and adolescents and potential effects of replacement therapy: a review. Eur J Endocrinol. 2013 Jan;168(1):R1-11.

5. Wasniewska M, Salerno M, Cassio A, Corrias A, Aversa T, Zirilli G, et al. Prospective evaluation of the natural course of idiopathic subclinical hypothyroidism in childhood and adolescence. Eur J Endocrinol. 2009 Mar; 160(3):417-21.

6. Rapa A, Monzani A, Moia S, Vivenza D, Bellone S, Petri A, et al. Subclinical hypothyroidism in children and adolescents: a wide range of clinical, biochemical, and genetic factors involved. J Clin Endocrinol Metab. 2009 Jul; 94(7):2414-20.

7. Lazarus J, Brown RS, Daumerie C, Hubalewska-Dydejczyk A, Negro R, Vaidya B. 2014 European thyroid association guidelines for the Management of Subclinical Hypothyroidism in pregnancy and in children. Eur Thyroid J. 2014 Jun;3(2):76-94.

8. Cerbone M, Bravaccio C, Capalbo D, Polizzi M, Wasniewska M, Cioffi D, et al. Linear growth and intellectual outcome in children with longterm idiopathic subclinical hypothyroidism. Eur J Endocrinol. 2011 Apr; 164(4):591-7.

9. Wasniewska M, Corrias A, Aversa T, Valenzise M, Mussa A, De Martino L, et al. Comparative evaluation of therapy with I-thyroxine versus no treatment in children with idiopathic and mild subclinical hypothyroidism Horm Res Paediatr. 2012;77(6):376-81.

10. Radetti G, Maselli M, Buzi F, Corrias A, Mussa A, Cambiaso P, et al. The natural history of the normal/mild elevated TSH serum levels in children and adolescents with Hashimoto's thyroiditis and isolated hyperthyrotropinaemia: a 3-year follow-up. Clin Endocrinol. 2012 Mar;76(3): 394-8.

11. Reinehr $\mathrm{T}$. Thyroid function in the nutritionally obese child and adolescent. Curr Opin Pediatr. 2011 Aug;23(4):415-20.

12. Cerbone M, Capalbo D, Wasniewska M, Mattace Raso G, Alfano S, Meli R, et al. Cardiovascular risk factors in children with long-standing untreated idiopathic subclinical hypothyroidism. J Clin Endocrinol Metab. 2014 Aug; 99(8):2697-703.

13. Such K, Gawlik A, Dejner A, Wasniewska M, Zachurzok A, Antosz A, et al. Evaluation of subclinical hypothyroidism in children and adolescents: a single-center study. Int J Endocrinol. 2016;2016:1-7.

14. Ergin Z, Savaş-Erdeve \$̦, Kurnaz E, Çetinkaya S, Aycan Z. Follow-up in children with non-obese and non-autoimmune subclinical hypothyroidism. J Pediatr Endocrinol Metab. 2018 Oct 25;31(10):1133-8.

15. Gammons S, Presley BK, White PC. Referrals for elevated thyroid stimulating hormone to pediatric endocrinologists. J Endocr Soc. 2019 Nov 1;3(11): 2032-40.

16. Radetti G, Kleon W, Buzi F, Crivellaro C, Pappalardo L, di lorgi N, et al. Thyroid function and structure are affected in childhood obesity. J Clin Endocrinol Metab. 2008 Dec;93(12):4749-54.

17. Grandone A, Santoro N, Coppola F, Calabrò P, Perrone L, del Giudice EM. Thyroid function derangement and childhood obesity: an Italian experience. BMC Endocr Disord. 2010 Dec 4;10(1):8.

18. Baş VN, Aycan Z, Ağladıoğlu SY, Kendirci HNP. Prevalence of hyperthyrotropinemia in obese children before and after weight loss. Eat Weight Disord - Stud Anorexia, Bulim Obes. 2013 Mar 3;18(1):87-90.

19. Reinehr T, Isa A, de Sousa G, Dieffenbach R, Andler W. Thyroid hormones and their relation to weight status. Horm Res. 2008;70(1):51-7.

20. Wolters B, Lass N, Reinehr T. TSH and free triiodothyronine concentrations are associated with weight loss in a lifestyle intervention and weight regain afterwards in obese children. Eur J Endocrinol. 2013 Mar;168(3):323-9.

21. Shalitin S, Yackobovitch-Gavan M, Phillip M. Prevalence of thyroid dysfunction in obese children and adolescents before and after weight reduction and its relation to other metabolic parameters. Horm Res. 2009; 71(3):155-61.

22. Wasniewska M, Aversa T, Salerno M, Corrias A, Messina MF, Mussa A, et al. Five-year prospective evaluation of thyroid function in girls with subclinical mild hypothyroidism of different etiology. Eur J Endocrinol. 2015;173:801-8.

23. Aversa T, Corrias A, Salerno M, Tessaris D, Di Mase R, Valenzise M, et al. Fiveyear prospective evaluation of thyroid function test evolution in children with Hashimoto's thyroiditis presenting with either Euthyroidism or subclinical hypothyroidism. Thyroid. 2016;26:1450-6.

24. Crisafulli G, Aversa T, Zirilli G, Pajno GB, Corica D, De Luca F, et al. Subclinical Hypothyroidism in Children: When a Replacement Hormonal Treatment Might Be Advisable. Front Endocrinol (Lausanne). 2019 Feb 25;10:109.

25. Lipp RW, Scherer T, Krebs M. Is Thyroxine therapy indicated in any case of subclinical hypothyroidism? Austrian J Clin Endocrinol Metab. 2013;6(2):12-6.

26. Vigone MC, Capalbo D, Weber G, Salerno M. MILD HYPOTHYROIDISM IN Childhood: who, when and how should be treated? J Endocr Soc. 2018 Jul 25:2(9):1024-39.

\section{Publisher's Note}

Springer Nature remains neutral with regard to jurisdictional claims in published maps and institutional affiliations. 